\title{
Integrated Traffic Flow Management Decision Making
}

\author{
Shon Grabbe ${ }^{*}$ and Banavar Sridhar ${ }^{\dagger}$ \\ NASA Ames Research Center, Moffett Field, CA, 94035-1000 \\ Avijit Mukherjee ${ }^{\ddagger}$ \\ University of California Santa Cruz, Moffett Field, CA, 94035-1000
}

\begin{abstract}
A generalized approach is proposed to support integrated traffic flow management decision making studies at both the U.S. national and regional levels. It can consider tradeoffs between alternative optimization and heuristic based models, strategic versus tactical flight controls, and system versus fleet preferences. Preliminary testing was accomplished by implementing thirteen unique traffic flow management models, which included all of the key components of the system and conducting 85, six-hour fast-time simulation experiments. These experiments considered variations in the strategic planning look-ahead times, the replanning intervals, and the types of traffic flow management control strategies. Initial testing indicates that longer strategic planning look-ahead times and re-planning intervals result in steadily decreasing levels of sector congestion for a fixed delay level. This applies when accurate estimates of the air traffic demand, airport capacities and airspace capacities are available. In general, the distribution of the delays amongst the users was found to be most equitable when scheduling flights using a heuristic scheduling algorithm, such as ration-by-distance. On the other hand, equity was the worst when using scheduling algorithms that took into account the number of seats aboard each flight. Though the scheduling algorithms were effective at alleviating sector congestion, the tactical rerouting algorithm was the primary control for avoiding en route weather hazards. Finally, the modeled levels of sector congestion, the number of weather incursions, and the total system delays, were found to be in fair agreement with the values that were operationally observed on both good and bad weather days.
\end{abstract}

\section{Introduction}

$\mathrm{T}$ RAFFIC flow management in the United States is largely accomplished under current day operations through a disparate collection of controls, such as miles-in-trail restrictions, playbook reroutes, airspace flow programs, and ground delay programs. These controls are, for the most part, implemented independent of one another, and their future interactions are typically not well understood. This results in a set of control actions that tend to under, over, and inconsistently control traffic flows, without fully accommodating user preferences. Automation to support the integrated assessment of these controls could promote an understanding of these interactions.

Several research organizations have proposed modeling techniques to examine the integrated impact of traffic flow management initiatives at the U.S. national-level. ${ }^{1-4}$ In Ref. 1 , an integrated three-step hierarchical method is proposed for developing deterministic traffic flow management plans consisting of national-level playbook reroutes, miles-in-trail restrictions, and tactical reroutes. A Monte Carlo-based incremental, probabilistic decision-making approach for developing en route traffic management controls is proposed in Ref. 2. Lastly, a sequential optimization approach is proposed in Refs. 3 and 4. It uses a deterministic integer programming model to strategically assign delays to flights, while tactical flight control heuristics are employed to reactively account for system uncertainties. One of the main concerns with these studies is the reliance on point design solutions (i.e., a

\footnotetext{
${ }^{*}$ Research Scientist, Systems Modeling \& Optimization Branch, Mail Stop 210-15, shon.grabbe@nasa.gov, Senior Member AIAA.

${ }^{\dagger}$ Senior Scientist, Aviation Systems Division, Mail Stop 210-10, Fellow AIAA.

${ }^{\ddagger}$ Associate Project Scientist, University of California Santa Cruz, Mail Stop 210-8.
} 
single model or algorithm is evaluated without considering the trade-offs between alternative models and algorithms).

In this study, a generalized approach is proposed and tested to support integrated traffic flow management decision making at both the U.S. national and regional levels. It can consider trade-offs between alternative optimization and heuristic based models, weather translation models ${ }^{5}$, strategic versus tactical flight controls $\mathbf{s}^{3,4,6,7}$, and service provider versus user preferences. Real-world scenarios that are derived from flight schedule data from August 24, 2005 and the convective weather avoidance model data ${ }^{8}$ from June 19, 2007 are used to test the initial implementation of the approach. For reference, June 19, 2007 was selected as a representative bad weather day. Different dates for the convective weather and aircraft schedule data were intentionally selected to ensure that control actions in response to the weather were not reflected in the flight schedule data.

Section II describes the key components, inputs, models, and interactions associated with the integrated traffic flow management decision-making approach. A discussion of the implemented models, flight schedules, weather scenarios, and airspace capacity constraints used in this study is presented in Section III. The experimental results of fast-time simulations used to explore trade-offs between optimization and heuristic based models, strategic versus tactical flight controls, and system versus fleet preferences are presented in Section IV. Finally, concluding remarks are presented in Section V.

\section{Integrated Traffic Flow Management Approach}

The major components of the approach that is being proposed to support integrated traffic flow management decision making are outlined in the flow control diagram appearing in Fig. 1. At the highest level, the components labeled "User schedules and flight plans," "Meteorological Data," and "Airspace Adaptation Data" supply input data to the National Airspace System (NAS) and to a lower-level control loop that is designed to develop traffic flow management controls at the national and regional level. The first step in developing these controls is in estimating, which is carried out in the box labeled "Demand Estimation," the forecasted demand at both airport and airspace resources, such as sectors, fixes, and jet routes. The output of this component is indicated by the arrow labeled [1] in Fig. 1. In parallel, the baseline capacities of both airport and airspace resources, which are obtained from the "Airspace Adaptation Data" component, are dynamically revised based on actual and forecasted weather conditions in the "Weather Translation" component. Additionally, this module will also forecast regions of airspace that pilots are likely to deviate around. 8 The output of the "Airspace Adaptation Data" component (see arrow [2] in Fig. 1) is time varying airport and airspace capacities and weather hazard contours, respectively, that take into account the effects of both convective and non-convective weather constraints.

With forecasted estimates of both demand and capacity (see arrows [1] and [2] in Fig. 1), the air traffic service provider (ATSP), which is the Federal Aviation Administration in the U.S., can identify locations forecasted to be congested, such as airports or sectors in which the demand is expected to exceed the capacity. In Fig. 1, the component designed to identify these constraints is labeled as "System Constraint Identification." The forecasted system constraints, demand estimates, and capacity estimates can be used by the ATSP to estimate the impact of these constraints on NAS operations using metrics, such as the number of sectors or airports where demand is expected to exceed available capacity, in the box labeled "System Impact Assessment". Similarly, under a collaborative decision making paradigm, ${ }^{9-11}$ the airspace users can assess the impact of these constraints on their flights while leveraging proprietary information, such as crew and passenger connectivity data, in the box labeled "Fleet Impact Assessment."

Following the impact assessment stages, a combination of both airborne and ground-based traffic flow management (TFM) controls that mitigate the impact of the system constraints, while accounting for the user's fleet preferences are developed in the "System Planning" and "Fleet Planning" modules. The "System Planning" module will leverage the state-of-the-art in scheduling and routing algorithms to assign controls to flows of aircraft or resources to individual users, as is done for ground delay programs and airspace flow programs. The "Fleet Planning" module will leverage user specific flight planning software to assign controls to individual flights to meet user specific goals, such as maintaining schedule integrity. The planning stages will be iterative (see arrows [6] and [7] in Fig. 1) to ensure that the often-opposing objectives of maintaining schedule integrity are balanced against the needs of maintaining an efficient air transportation system. The output of the planning stages consists of a set of TFM controls that are subsequently implemented in the NAS (see arrow [11] in Fig. 1). 


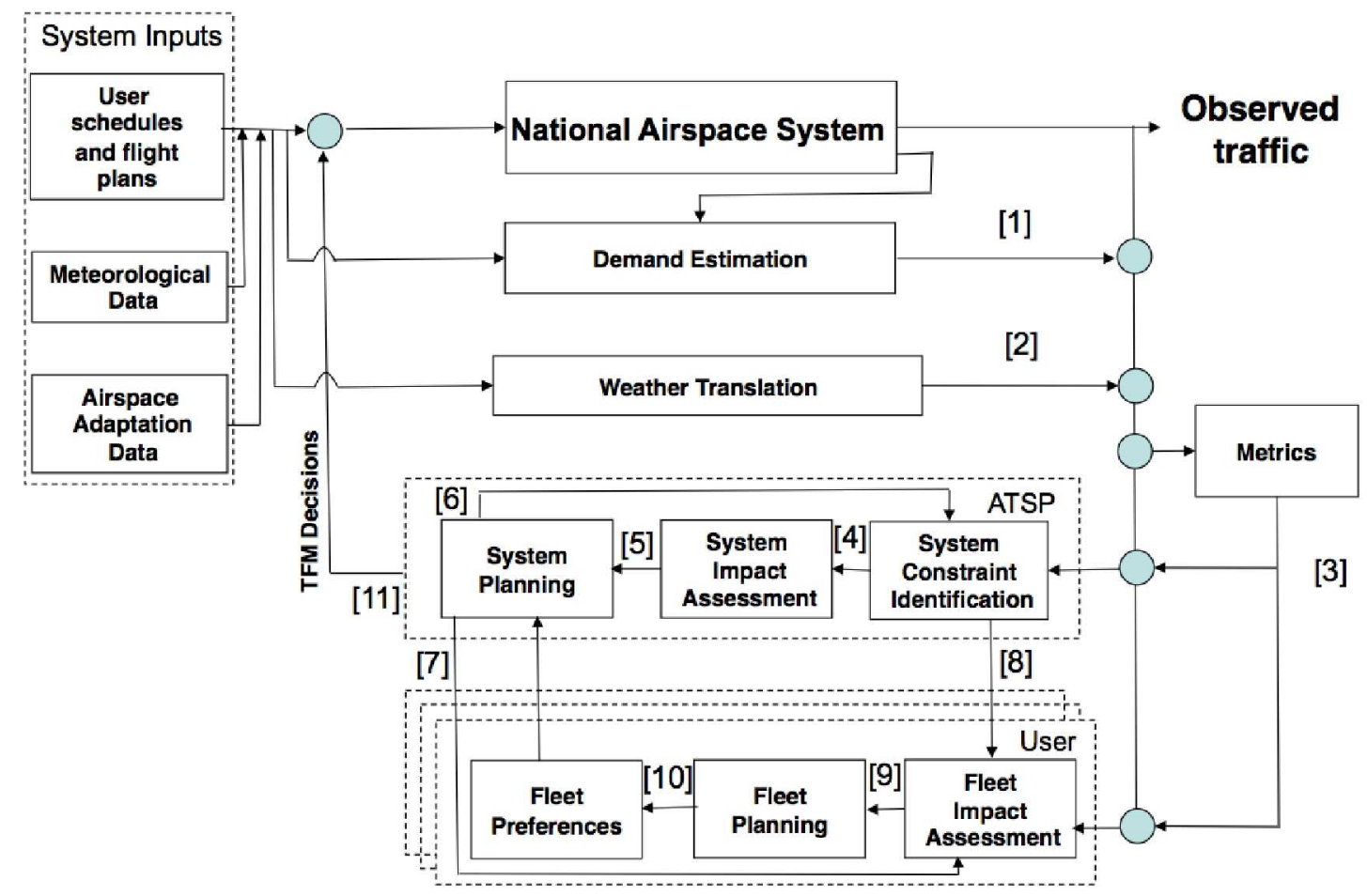

Figure 1. Integrated traffic flow management architecture.

A more detailed description of each of these individual components, key data sources used by each component, and sample models supporting each component follow:

\section{System Inputs:}

For strategic TFM planning, flight schedules will be developed using a combination of data available from the Official Airline Guide (OAG) in order to derive flight plan intent and estimates of the unimpeded (e.g., without ground and airborne holding) flight demand. ${ }^{12}$ As in current operations, the users will provide updates to this nominal schedule approximately one hour prior to departure via the Host computer at the Air Route Traffic Control Center (ARTCC) from which the flight is departing. This current mode of updating the flight intent information has a number of well documented limitations. ${ }^{12}$ One of the most important is the lack of ability to provide updated flight intent information sufficiently early in the planning process to be useful for strategic planning purposes. To overcome this problem, the FAA has instituted a program by which the users can submit directly to the Enhanced Traffic Management System (ETMS) ${ }^{13}$ early intent information anytime up to 24 hours prior to departure.

The meteorological inputs to the integrated TFM approach consist of both convective, such as echo top and storm intensity data, and non-convective inputs, such as winds and icing data. A summary of convective weather products available for TFM planning is summarized in Refs. 14 and 15. For planning in the twenty minute to six hour time frame, the most relevant convective weather products are Next Generation Radar (NEXRAD), which provides surveillance data; the Corridor Integrated Weather System (CIWS), which provides forecasts in the five minute to two hour time horizon; and National Convective Weather Forecast - 6 (NCWF6), which provides a one to six hour forecast. In terms of non-convective meteorological data, Ref. 16 provides a detailed causality analysis of the impact of these data sources on air traffic management operations. Among the more important non-convective weather products that are predictable over the twenty minute to six hour planning horizon are winds-aloft, which are available from the Rapid Update Cycle (RUC) model $^{17}$; and ceiling and visibility forecasts, which are available from the marine stratus forecast system. ${ }^{18}$

The ETMS $^{12}$ will provide airspace adaptation data for current day planning on a 56-day update cycle. ETMS contains, for example, static definitions of sector boundaries, monitor alert parameters (MAP) for each of these sectors, and airway definitions. In the future, airspace definitions are likely to be more adaptable based on traffic demand, equipage, and weather. ${ }^{19}$ Sophisticated algorithms, such as those described in Ref. 20 may be used to dynamically design and provide the airspace adaptation data needed for TFM planning. 


\section{Demand Estimation:}

Estimates of the demand at NAS resources, such as sectors, airports, and airways, can be calculated using either aircraft-level, physics-based models, which calculate four-dimensional trajectories for individual flights, or aggregate models. Examples of systems using physics-based models include the Center TRACON Automation System $^{21}$, the Future ATM Concepts Evaluation Tool (FACET) ${ }^{22}$, and the Collaborative Routing Coordination Tool (CRCT) ${ }^{23}$ Because of the numerous sources of trajectory prediction uncertainty in the NAS ${ }^{24}$, these models tend to only provide accurate demand estimates over the 0 to 30 minute planning horizon. Therefore to extend the utility of these predictions to support strategic TFM planning, it is desirable to quantify the uncertainty in these predictions as is done in Ref. 25.

As an alternative, aggregate traffic flow models for strategic TFM planning have recently been a topic of considerable interest. A complete summary of these models is provided in Ref. 26. Among the more notable models to appear in the literature are the initial Eulerian model ${ }^{27}$, an aggregate stochastic dynamic model that accounts for the inherent departure time uncertainty at airports ${ }^{28}$, and a multi-commodity large-capacity cell transmission model. ${ }^{29}$ These models have been shown to accurately forecast the demand in both sectors and centers over a time horizon that supports strategic traffic flow planning,

\section{Weather Translation:}

Weather translation refers to the process of converting raw meteorological data into Air Traffic Management (ATM) impacts. For TFM planning, this entails identifying regions of airspace that aircraft are likely to avoid and calculating the weather impacted capacities of NAS resources, such as airports, fixes, and sectors. The Convective Weather Avoidance Model (CWAM) ${ }^{8}$ is currently the state-of-the-art model for translating over a two-hour planning horizon meteorological data, such as precipitation intensity and storm height, into aircraft deviation probability contours. These contours are calculated between $24,000 \mathrm{ft}$ and $44,000 \mathrm{ft}$ in $1,000 \mathrm{ft}$ increments, with deviation probabilities that range from $0 \%$ to $100 \%$. Beyond the two-hour planning horizon, limited research ${ }^{29}$ that identifies regions of airspace that aircraft are likely to avoid has been conducted that identifies regions of airspace, and this is considered to be a major research gap.

In parallel with the research designed to identify weather-impacted regions of the NAS, a number of approaches have been developed to calculate the aggregate impact of these regions on NAS resources, such as sectors. ${ }^{30-35}$ For example, in Ref. 31 a simple 2D weather coverage model is compared to a 3D weather coverage model and a flow blockage model. The Weather Impacted Traffic Index (WITI) metric ${ }^{36}$ is extended in Ref. 32 to estimate airspace capacity, while a sector scanning approach is proposed in Ref. 33.

\section{ATSP Planning:}

Once forecasted estimates of the demand and capacity of the NAS resources have been calculated, the ATSP uses this data to perform the following high-level tasks: System Constraint Identification, System Impact Assessment, and System Planning (see Fig. 1). The classification of these tasks is consistent with the classification outlined in Ref. 37 except the demand and capacity estimation components have been explicitly labeled in the current study. System Constraint Identification involves identifying NAS resources for which the forecasted demand is expected to exceed the available capacity. Using the integer programming (IP) formulation presented in Refs. 3 and 4, the airports and sectors for which a constraint exists can be expressed mathematically as is done in the Appendix.

Once the system constraints are identified, using Eqs. (1)-(3) for example, a decision is made in the System Impact Assessment module regarding the need for further flight- or flow-based control actions. Ideally, this assessment will take into account both the severity and likelihood of the constraint materializing, and whether the constraint is a hard constraint, which cannot be violated, or a soft constraint, which can be violated to a certain extent. A set of control actions, which is likely to include any or all of the following: airborne delays, reroutes, and ground delays, is subsequently developed in the System Planning module to alleviate the forecasted system constraints. Additionally, the System Planning module will also reevaluate any previously imposed constraints, such as pre-departure delays or weather avoidance routes, to determine if these controls should be modified or removed. Examples in which this reevaluation occurred every two- and three-hours, respectively, are presented in subsection IV.A, but the actual frequency at which this reevaluation should occur is considered to be an open area of research.

A number of both optimization- and heuristic-based models have recently appeared in the literature for accomplishing individual components or all of the activities associated with the ATSP planning. These range from simple sorting rules, such as First-Come-First-Served (FCFS), to more sophisticated binary integer programming 
models, such as the ones proposed in Refs. 38 and 39, which decide on the amount of ground and airborne holding to assign to individual flights under airport and airspace capacity constraints. Additionally, Ref. 40 proposed a heuristic based approach that approximately minimizes delay and schedule deviation, while Ref. 41 presented single- and multi-pass heuristic dispatching rule algorithms for assigning airborne and ground delays to flights subject to sector capacity constraints.

\section{User Planning:}

Closely paralleling the ATSP planning activities are the high-level user planning tasks that have been labeled in Fig. 1 "Fleet Impact Assessment" and "Fleet Planning." Both of these tasks are for the most part proprietary and rely to a large extent on the business models of the individual users. The Fleet Impact Assessment task will likely examine key factors such as fuel capacity, crew availability, flight connectivity, passenger connectivity and gate availability. ${ }^{42}$ The Fleet Planning task may leverage a variant of the airline schedule recovery model proposed in Ref. 43 or the fleet assignment model proposed in Ref. 44. User preference into the System Planning task can subsequently be implemented using the credit-based concept proposed in Ref. 45 (see arrow [10] in Fig. 1). Additionally, parallel research efforts that are explicitly focused on developing algorithms to support collaboration between the users and the ATSP are currently under way ${ }^{46}$.

\section{Metrics:}

In order to evaluate the impact of the TFM decisions on both the system performance and the users, it is necessary to characterize and model various metrics. The definition and implementation of metrics suitable for characterizing the impact of TFM decisions on the NAS is a rich area of research that has received considerable interest in recent years. ${ }^{36,47,48}$ Metrics currently exist or have been proposed for estimating delays, safety, predictability, flexibility, and efficiency. For example, Refs. 49-52 have proposed, implemented and tested metrics for correlating the performance of the NAS with respect to the weather using a concept referred to as the Weather Impacted Traffic Index (WITI). ${ }^{36}$ Models for exploring the propagation of delays throughout the NAS have been examined in Refs. 53-55, and models for estimating the delays incurred by passengers have been examined in Ref. 56.

\section{Experimental Setup}

This section describes the system inputs, weather translation models, constraint identification process, impact assessment, planning, and metrics used for testing the integrated TFM approach proposed in Section II. For consistency with the previous section, these elements will be organized with respect to the high-level modules outlined in Section II.

\section{System Inputs:}

For all experimental runs, inputs to the "User schedules and flight plans" module in Fig. 1 were derived from the August 24, 2005 ETMS data set. The ETMS data parsing logic in FACET was used to extract: departure messages (DZ), flow control track/flight data block messages (TZ), and flight plan messages (FZ) to generate the inputs for the fast-time simulations. The TZ messages were used to establish an initial position for each flight. The FZ messages were used to assign baseline flight paths to each flight. The DZ messages were used to establish departure times. All experimental runs were assumed to start at 6:00 am Eastern Daylight Time (EDT), and end at 12:00 pm EDT.

The "Meteorological Data" depicted in Fig. 1 consisted of actual and forecasted CIWS data from June 19, 2007. For reference, the actual NEXRAD weather observations for each of these days at 2:00 pm EDT is illustrated in Fig. 2. June 19, 2007 was selected as a representative "bad weather day," which was characterized by an intense line of thunderstorms that extended from the U.S.-Canadian border down into Memphis Center, as illustrated by Fig 2a. According to the FAA's Operations Network (OPSNET), ${ }^{57}$ this weather pattern resulted in over 200,000 minutes of flight delay. 


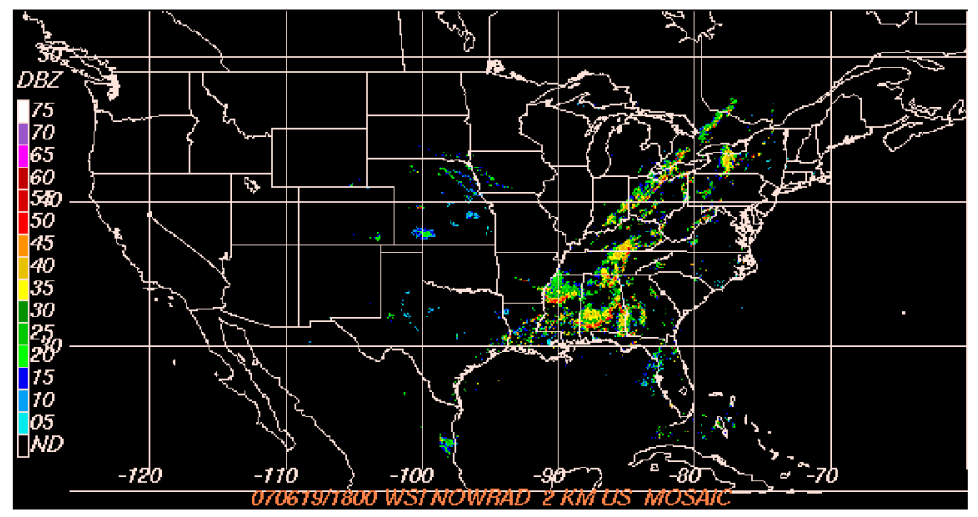

Figure 2. NEXRAD weather observations at 2:00 pm EDT on June 19, 2007 (bad weather day).

\section{Weather Translation:}

As was described in Section II, the raw CIWS data was subsequently converted prior to being used for developing the TFM control strategies into ATM impacts in the module labeled "Weather Translation" in Fig. 1. The first step in this translation process consisted of converting the raw CIWS data into Convective Weather Avoidance Model (CWAM) deviation probability contours. ${ }^{8}$ The CWAM contours were used to calculate weather impacted sector capacities using the flow blockage based weather translation module proposed in Ref. 31.

\section{ATSP Planning:}

The first step in the ATSP Planning process is "System Constraint Identification" (see Fig. 1). For the purpose of the strategic scheduling models, which will be described later in this subsection, these constraints are identified using Eqs. (1)-(3). The outcome of this step is a list of airports and/or sectors for which the forecasted or actual demand exceeds the capacity of the respective resources. When tactical rerouting is employed as part of the integrated TFM solution, the system constraints will consist of a list of the aforementioned CWAM $60 \%$ probability deviation contours. This contour level is being used, because Ref. 4 showed that these are reasonable representations of the regions of airspace that flights typically avoid.

In the second step of the ATSP Planning process, "System Impact Assessment", a decision is made regarding the extent to which flights that require access to the constrained regions of the NAS will be controlled. From an operational perspective, this would be useful because depending on factors, such as the confidence in the weather forecasts, demand estimates, and capacity estimates, one might choose to adopt either a conservative strategy and strictly adhere to the guidance of the automation or an aggressive strategy and ignore the automation. Examples in which six alternative responses are considered are presented and discussed in Section IV.

The final step of the ATSP Planning process is "System Planning." For initial testing of the integrated traffic flow management system, subsets of models that have appeared in the literature were selected to allow for an objective comparison of alternative tactical and strategic, and heuristic and optimization based control strategies. These models, which are described next, were selected based on the availability and maturity of the underlying algorithms.

\section{Let,}

$F(t)=$ set of all controllable flights at time $\mathrm{t}$

$F_{G}(t)=$ subset of $F(t)$ on the ground at time $\mathrm{t}$

$F_{A}(t)=$ subset of $F(t)$ in the air at time $t$

$D_{j}(t)=$ demand associated with the unscheduled airborne flights in sector $\mathrm{j}$ at time $\mathrm{t}$

$W_{j}(t)=$ reduction in capacity of sector $j$ at time $t$ as a result of the CWAM $60 \%$ deviation probability contours

The thirteen "System Planning" models implemented for this study are defined in Table 1. For the ration-byschedule (RBS) models (rows 2-4), $F(t)$ is ordered by increasing scheduled departure times, and flights are scheduled subject to the airport and sector capacity constraints defined in Eqs. (1)-(3). Note that the greater than signs in Eqs. (1)-(3) must be replaced with a less than signs to form these constraints. The ration-by-distance (RBD) 
models in rows 5-7 order the flights in $F(t)$ by decreasing flight path distance (i.e., flights traveling the longest distances are scheduled first). The set of flights, $F(t)$, is ordered by decreasing "congestion score" (i.e., flights using the fewest number of congested airports and sectors are scheduled first) for the ration-by-congestion models (see rows 8-10). This score was assigned using the methodology described in Ref. 58. For the ration-by-passenger models (see rows 11-13), $F(t)$ is ordered by decreasing levels of passengers on each flight (i.e., flights with the most passengers are scheduled first.). Passenger loading data was derived from data provided in the Bureau of Transportation Statistics Schedule B-43 Aircraft Inventory database. ${ }^{59}$ For simplicity, the passenger loading was assumed to be equal to the number of seats on each flight. This is admittedly an oversimplification, which will be refined in support of future research activities. The last scheduling algorithm considered was the deterministic integer-programming (IP) model (see row 14) that was described in Refs. 3 and 4. This model assign pre-departure delays to flights while minimizing the total ground delay with respect to the unconstrained schedule. To improve the computational runtime of this model, only flights with high "congestion scores" were scheduled. Flights with low "congestion scores" were treated as background traffic. Here the "congestion score" is calculated using the method described in Ref. 58. For all applications of this model, the maximum number of flights that were scheduled was 1,500 , which was about one-fourth of the flights that required scheduling over a three hour planning horizon. The resulting integer-programming model contained slightly over 200,000 variables and constraints, and was typically solved in about five minutes.

The models listed in rows $4,7,10$, and 13 of Table 1 all leverage the tactical weather avoidance routing algorithms described in Ref. 4 to keep flights from deviating into actual and forecasted regions with CWAM $60 \%$ deviation probability contours. Weather avoidance reroutes were developed using a grid-based Dijkstra algorithm ${ }^{60}$ where link costs were proportional to the link distance and a penalty function was applied when the link intersected a weather hazard. Flight rerouting occurs at a five minutes update interval and two-hour CWAM forecasts were used in developing the weather avoidance routes. It is worth noting that this simplistic rerouting approach did not take into account sector capacities when establishing the reroutes. In a future study, both en route weather hazards and sector capacities will be considered. Throughout the remainder of this manuscript, "RTE" is used in the model names to indicate that tactical weather avoidance reroutes are being assigned to flights.

\section{User Planning:}

Since fleet planning is a complex task that varies from user to user and leverages proprietary information and software, no attempt has been made to model the "Fleet Impact Assessment" and "Fleet Planning" activities in the current study. However to account for alternative user preferences, which is represented by arrow [10] in Fig. 1, the scheduling algorithms described above have been adopted to explore alternative preferences that users might assign to their flights. 
Table 1. Description of the 13 aircraft-level models used for "System Planning."

\begin{tabular}{|c|c|c|c|c|}
\hline $\begin{array}{c}\text { Row } \\
\#\end{array}$ & Model Name & Controls & $\begin{array}{c}\text { Controllable } \\
\text { Flights } \\
F(t) \\
\end{array}$ & $\begin{array}{c}\text { Sector Capacities } \\
S_{j}(t)\end{array}$ \\
\hline 1 & RBS GND & - Pre-departure delays & $F(t)=F_{G}(t)$ & $S_{j}(t)=\max \left(S_{j}(t)-D_{j}(t)-W_{j}(t), 0\right)$ \\
\hline 2 & $\begin{array}{c}\text { RBS } \\
\text { AIR+GND }\end{array}$ & $\begin{array}{l}\text { - Airborne holding } \\
\text { - Pre-departure delays }\end{array}$ & $F(t)=F_{A}(t) \bigcup F_{G}(t)$ & $S_{j}(t)=\max \left(S_{j}(t)-W_{j}(t), 0\right)$ \\
\hline 3 & $\begin{array}{c}\text { RBS } \\
\text { AIR+GND+ } \\
\text { RTE }\end{array}$ & $\begin{array}{l}\text { - } \text { Airborne holding } \\
\text { - } \quad \text { Tre-departure delays } \\
\text { Tactical Rerouting }\end{array}$ & $F(t)=F_{A}(t) \bigcup F_{G}(t)$ & $S_{j}(t)=\max \left(S_{j}(t)-W_{j}(t), 0\right)$ \\
\hline 4 & RBD GND & - Pre-departure delays & $F(t)=F_{G}(t)$ & $S_{j}(t)=\max \left(S_{j}(t)-D_{j}(t)-W_{j}(t), 0\right)$ \\
\hline 5 & $\begin{array}{c}\text { RBD } \\
\text { AIR+GND }\end{array}$ & $\begin{array}{ll}\text { - } & \text { Airborne holding } \\
\text { - } & \text { Pre-departure delays }\end{array}$ & $F(t)=F_{A}(t) \bigcup F_{G}(t)$ & $S_{j}(t)=\max \left(S_{j}(t)-W_{j}(t), 0\right)$ \\
\hline 6 & $\begin{array}{l}\text { RBD } \\
\text { AIR+GND+ } \\
\text { RTE }\end{array}$ & $\begin{array}{ll}\text { - } & \text { Airborne holding } \\
\text { - } & \text { Pre-departure delays } \\
\text { Tactical Rerouting }\end{array}$ & $F(t)=F_{A}(t) \bigcup F_{G}(t)$ & $S_{j}(t)=\max \left(S_{j}(t)-W_{j}(t), 0\right)$ \\
\hline 7 & RBC GND & - Pre-departure delays & $F(t)=F_{G}(t)$ & $S_{j}(t)=\max \left(S_{j}(t)-D_{j}(t)-W_{j}(t), 0\right)$ \\
\hline 8 & $\begin{array}{c}\mathrm{RBC} \\
\mathrm{AIR+GND}\end{array}$ & $\begin{array}{ll}\text { - } & \text { Airborne holding } \\
\text { - Pre-departure delays }\end{array}$ & $F(t)=F_{A}(t) \bigcup F_{G}(t)$ & $S_{j}(t)=\max \left(S_{j}(t)-W_{j}(t), 0\right)$ \\
\hline 9 & $\begin{array}{l}\text { RBC } \\
\text { AIR+GND+ } \\
\text { RTE }\end{array}$ & $\begin{array}{l}\text { - Airborne holding } \\
\text { - Pre-departure delays } \\
\text { - Tactical Rerouting }\end{array}$ & $F(t)=F_{A}(t) \bigcup F_{G}(t)$ & $S_{j}(t)=\max \left(S_{j}(t)-W_{j}(t), 0\right)$ \\
\hline 10 & RBP GND & - Pre-departure delays & $F(t)=F_{G}(t)$ & $S_{j}(t)=\max \left(S_{j}(t)-D_{j}(t)-W_{j}(t), 0\right)$ \\
\hline 11 & $\begin{array}{c}\text { RBP } \\
\text { AIR+GND }\end{array}$ & $\begin{array}{l}\text { - } \text { Airborne holding } \\
\text { - Pre-departure delays }\end{array}$ & $F(t)=F_{A}(t) \bigcup F_{G}(t)$ & $S_{j}(t)=\max \left(S_{j}(t)-W_{j}(t), 0\right)$ \\
\hline 12 & $\begin{array}{l}\text { RBP } \\
\text { AIR+GND+ } \\
\text { RTE }\end{array}$ & $\begin{array}{ll}\text { - } & \text { Airborne holding } \\
\text { - } & \text { Pre-departure delays } \\
\text { Tactical Rerouting }\end{array}$ & $F(t)=F_{A}(t) \bigcup F_{G}(t)$ & $S_{j}(t)=\max \left(S_{j}(t)-W_{j}(t), 0\right)$ \\
\hline 13 & IP GND & - Pre-departure delays & $F(t)=F_{G}(t)$ & $S_{j}(t)=\max \left(S_{j}(t)-D_{j}(t)-W_{j}(t), 0\right)$ \\
\hline
\end{tabular}

Metrics:

The impact of the modeling approaches on NAS operations under the two weather scenarios will be quantified in terms of the metrics that are summarized in Table 2. 
Table 2. Metrics used to assess the performance of the integrated traffic flow management decision making system.

\begin{tabular}{|c|c|}
\hline Metric & $\begin{array}{ll} & \text { Description } \\
\end{array}$ \\
\hline Delay & $\begin{array}{l}\text { - Measures the cumulative deviation in arrival time for all flights from their } \\
\text { unconstrained scheduled arrival times in minutes. } \\
\text { - Delay }=\sum_{i=1}^{|F|}\left(t_{i}-t_{i}^{\prime}\right) \text { where } t_{i} \text { is the unconstrained scheduled arrival time for flight } i \\
\text { and } t_{i}^{\prime} \text { is the controlled scheduled arrival time }\end{array}$ \\
\hline $\begin{array}{c}\text { Sector } \\
\text { Congestion }\end{array}$ & $\begin{array}{l}\text { Measures the cumulative number of instances that the demand in a sector exceeds the } \\
\text { weather impacted capacity of the sector } \\
\text { - Sector Congestion }=\sum_{j, t} \delta_{j t} \text { where } \delta_{j t}=\left\{\begin{array}{l}1, \text { if Eq. } 3 \text { is true } \\
0, \text { otherwise }\end{array}, \forall j \in J, t \in\{1, \ldots, T\}\right.\end{array}$ \\
\hline \multirow[t]{2}{*}{$\begin{array}{l}\text { Weather } \\
\text { Incursions } \\
\text { Equity (Average } \\
\text { Airline Delay) }\end{array}$} & $\begin{array}{l}\text { - Measures the cumulative number of instances that flights intersect a region of } \\
\text { convective weather defined by the CWAM } 60 \% \text { deviation probability contours } \\
\text { - Measures the equality in the distribution of the average airline delay amongst all NAS } \\
\text { users with the Gini coefficient }{ }^{61}\end{array}$ \\
\hline & $\begin{array}{l}\text { Equity (Avg. Airline Delay) }=\frac{i=1 j=1}{2 n \sum_{i=1}^{n} x_{i}} \text {, where } x_{i} \text { is the average delay for all } \\
\text { flights in airline } i \text { and } n \text { is the number of airlines. }\end{array}$ \\
\hline $\begin{array}{l}\text { Equity (Maximum } \\
\text { Airline Delay) }\end{array}$ & $\begin{array}{l}\text { - Measures the equality in the distribution of the maximum airline delay amongst all } \\
\text { NAS users with the Gini coefficient }{ }^{61} \\
\text { - Calculated using the expression provided in the description of the "Equity (Average } \\
\text { Airline Delay)," with } x_{i} \text { as the maximum delay for all flights in airline } i \text {. }\end{array}$ \\
\hline
\end{tabular}

\section{Results}

This section contains the results of ninety-seven, six hour fast time simulation experiments to assess the ability of the proposed integrated TFM decision making approach to assign strategic pre-departure delays, airborne delays, and tactical reroutes subject to the airport and airspace capacity constraints described in Section III. Variations in the planning duration and look-ahead time and the scheduling and rerouting models were examined in terms of the number of instances where demand exceeded capacity, the number of instances that flights deviated into en route weather hazards, and the equity of the ensuing traffic flow management decisions. For convenience, the model naming convention introduced in Section III (e.g., RBS AIR+GND+RTE) will be used when labeling the results appearing in all figures in this section.

\section{A. Variations in Planning Duration and Look-ahead Time}

Plots of the sector congestion and the number of weather incursions as a function of the total delay when variations in the strategic planning duration and look-ahead time are considered are presented in Figs. 3a and 3b, respectively. Four of the heuristic scheduling algorithms described in Section III (i.e., RBS AIR+GND, RBD AIR+GND, RBP AIR+GND, and RBC AIR+GND) were used to assign both airborne and pre-departure delays in 
generating these results, and two re-planning scenarios were considered. In the first scenario, the strategic scheduling algorithms were run every two-hours with a two-hour look-ahead time. For the second scenario, replanning occurred every three-hours with a three-hour look-ahead time. The look-ahead time influences the number of flights that are included in the scheduling algorithms. For example, with a three-hour look-ahead time all flights that depart during that interval will be scheduled when using an algorithm such as RBS GND. "2hr" and " $3 \mathrm{hr}$ " descriptors are included in the legend entries in Figs. 3 and 4 to distinguish between these re-planning parameters. Additionally, the "AIR+GND" designator associated with each of the legend entries is used to indicate that the strategic scheduling algorithms were assigning both airborne and pre-departure delays to each flight.

Each of the scheduling models was run under six different conditions in order to simulate different ATSP responses in the "System Impact Assessment" decision-block in Fig. 1. The extremes of these system impact assessment approaches are clearly visible in Fig. 3. The left-most data points appearing on each of the curves (represented by open circles and squares) represents the case in which the ATSP chooses to ignore the "System Constraint Identification" results (see Fig. 1) and does not implement any strategic controls. Since the tactical rerouting algorithm was not run for the experiments in this subsection, no delay is incurred in the "System Planning" decision-box appearing in Fig. 1. For each of the scheduling algorithms, this leads to over $\mathbf{5 7 2}$ instances for which the demand exceeded the capacity, and 11,411 instances in which flights intruded into CWAM $60 \%$ deviation probability contours. The right-most data points appearing on each of the curves (indicated by open circles and squares) represents the case in which the ATSP treats all constraints from "System Constraint Identification" as binding. In this case, a combination of both airborne and pre-departure delay is applied to ensure that the air traffic demand does not exceed the available airport and airspace capacities. The sector congestion in Fig. 3a is non-zero for these cases because a number of en route flights started in sectors for which the demand exceeded capacity. The intermediate data points along each curve are generated by adopting "System Impact Assessment" strategies that become steadily less aggressive as one moves from the right to the left along each curve. To generate the four intermediate data points, fast time simulation experiments were conducted in which the delays assigned to the first $200,400,600$ and 800 flights, respectively, were ignored. By ignoring these delays an increasing number of formerly binding airport and airspace constraints were violated, which gives rise to the increasing levels of sector congestion that are observed in Fig. 3a.

In terms of the over-all levels of sector congestion, the ration-by-schedule (RBS) algorithm tended to result in the lowest levels of congestion, while the ration-by-distance (RBD) and ration-by-congestion (RBC) scheduling algorithms resulted in the most congestion. Decreasing the planning look-ahead time and the re-planning interval resulted in steadily increasing levels of sector congestion for a given level of delay. For example, when the RBS algorithm is run every three-hours with a three-hour look-ahead time (solid black curve) 400 units of sector congestion are achieved through 25,000 minutes of delay. When the same algorithm is run every two-hours with a two-hour look-ahead time (dash-dot black curve), 400 units of sector congestion are achieved through 35,000 minutes of delay.

Although none of the scheduling algorithms explicitly attempt to keep flights from deviating into the CWAM $60 \%$ deviation contours, each algorithm does limit the number of flights flowing through sectors impacted by these contours. As illustrated in Fig. 3b, the order in which flights are scheduled through these weather-impacted sectors, strongly influences the number of flights intruding into these weather hazards. For example, the minimum number of weather incursions over the six-hr planning horizon was observed to be 9,592 with 23,754 minutes of delay when scheduling flights with the ration-by-congestion (RBC) model that was run every three-hours. With the same amount of delay, the ration-by-distance (RBD) algorithm with a three-hour re-planning interval resulted in roughly 11,000 weather incursions. Unlike the sector congestion trends observed in Fig. 3a, a strong correlation between the number of binding constraints and the number of weather incursions was not observed. In fact, for several of the algorithms the smallest number of weather incursions was observed when a significant number of the airport and airspace constraints were non-binding. The effect of re-planning duration and look-ahead time on the number of weather incursions varied significantly with the scheduling algorithm. For the ration-by-distance (RBD) and rationby-passenger (RBP) algorithms, the two-hour and three-hour re-planning yielded very similar results, especially for the low delay cases. Other algorithms, such as ration-by-congestion (RBC), resulted in significantly fewer weather incursions as the re-planning interval increased. A significant conclusion that can be drawn from the results presented in Fig. 3 is that without explicitly taking into account the impact of weather on traffic flows in the strategic scheduling algorithm, there is no guarantee that reductions in the levels of sector congestion (see Fig. 3a) will result in corresponding decreases in the number of weather incursions (see Fig. 3b). 


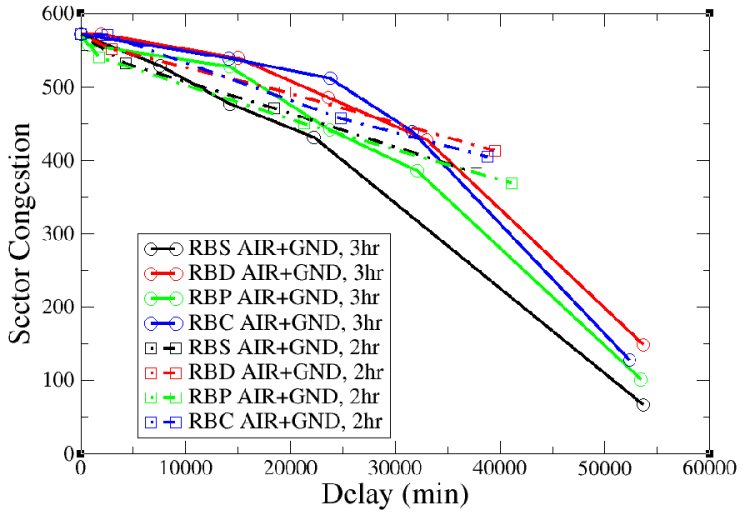

[a]

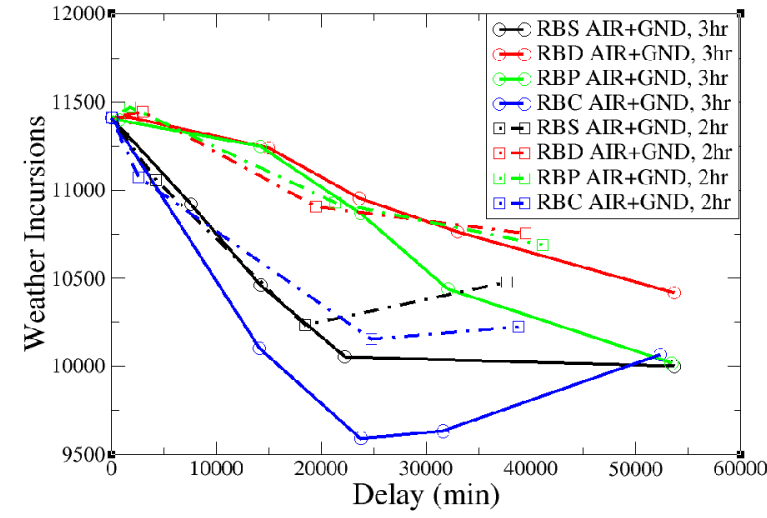

[b]

Figure 3. Impact of strategic planning look-ahead time and re-planning frequency on [a] the amount of sector congestion and $[b]$ the number of instances that flights deviated into a region of convective weather for a bad weather day (June 19, 2007).

The equity of the scheduling results from the airline's perspective, as measured by the Gini coefficient ${ }^{61}$, are presented in Fig. 4. All results in this figure are for the bad weather day (June 19, 2007), and the heuristic scheduling algorithms are allowed to assign both airborne and pre-departure delays, and all constraints are treated as binding constraints. When the equity is calculated using the average airline delay (see Fig. 4a), the ration-bypassenger (RBP) results are found to be the least equitable, while the ration-by-schedule (RBS) and ration-bydistance (RBD) algorithms were the most equitable. In general, the re-planning duration and look-ahead time did not significantly alter the equity results appearing in Fig. 4. When airline equity is calculated using the maximum airline delay (see Fig. 4b), all of the heuristic scheduling algorithms were found to be fairly equitable, and no one algorithm performed significantly better or worse than another algorithm.

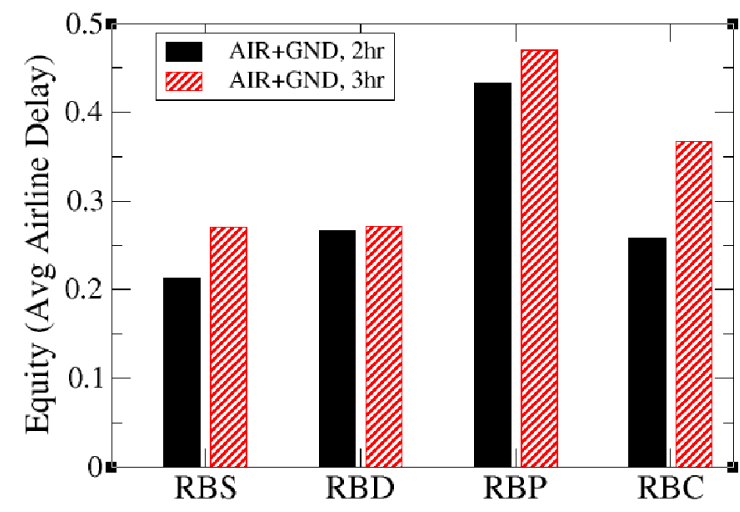

[a]

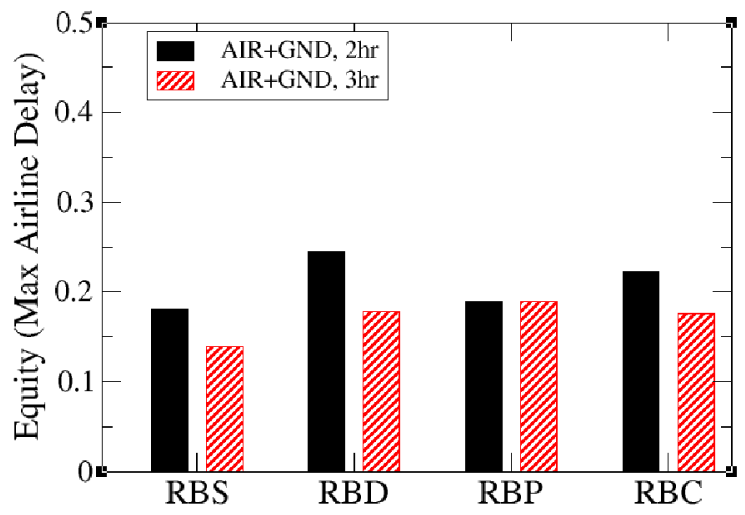

[b]

Figure 4. Impact of strategic planning look-ahead time and re-planning frequency on [a] airline equity calculated from the average airline delay and [b] airline equity calculated from the maximum airline delay for a bad weather day (June 19, 2007).

\section{B. Ground Holding versus Airborne and Ground Holding}

Results illustrating the variations in the sector congestion and the number of weather incursions as a function of the total scheduling delay are presented in Fig. 5, respectively. In generating these results, the scheduling algorithms are allowed to assign delays under two different conditions. In the first condition, the algorithms assign only predeparture delay (dash-dot curves in Fig. 5) while in the second condition the algorithms can assign pre-departure and airborne delays (solid curves in Fig. 5). Tactical weather avoidance routing was not allowed for the scenarios considered in this sub-section, and re-planning occurred every three-hours with a three-hour look-ahead time.

As illustrated by Fig. 5a, for a given level of congestion, the scheduling algorithms tend to assign fewer delays when only pre-departure delays are assigned. For example, with the ration-by-schedule (RBS) algorithm that assigns ground controls only (black dash-dot curve in Fig. 5a), 100 units of sector congestion are achieved by 
assigning roughly 30,000 minutes of delay. However to achieve the same level of sector congestion with the RBS algorithm that assigns pre-departure and airborne delay (solid black curve in Fig. 5a) over 50,000 minutes of delay is required. To understand this behavior, it is important to recall from Section III how the sector capacities are calculated for the scheduling algorithms. Starting with nominal monitor alert parameters for each of the sectors, a weather translation model is used to calculate weather impacted sector capacities. These weather impacted sector capacities are subsequently reduced by the time-varying demand associated with the unscheduled flights. When the scheduling algorithms assign both airborne and pre-departure delays, there are no unscheduled flights. However when only pre-departure delays are assigned, all airborne flights are treated as background traffic. Since the sector capacities must be nonnegative values, the scheduling algorithms that assign ground holding only, often have to "create" capacity to accommodate any unscheduled en route flights.

The number of weather incursions after running the scheduling algorithms was found to vary significantly depending on the type of scheduling algorithm that was used and the flights being delayed by the algorithm. As previously mentioned, the ration-by-congestion (RBC) algorithm resulted in the fewest number of weather incursions when only a sub-set of the system constraints were binding. The algorithm performed equally well whether it was allowed to assign pre-departure delays only (dash-dot blue curve in Fig. 5b), or whether it assigned pre-departure and airborne delays (solid blue curve in Fig. 5b). Similar trends were noted for the ration-by-schedule (RBS) algorithm (black curves in Fig. 5b). For a given weather incursion level, the ration-by-distance (RBD) and ration-by-passenger (RBP) algorithms resulted in significantly less delay when the scheduling algorithm assigned pre-departure delays only. It is worth noting that the integer-programming based departure control model (IP GND) performed quite well both limiting sector congestion and the number of weather incursions despite the fact that the model was only allowed to schedule a maximum of 1,500 flights.

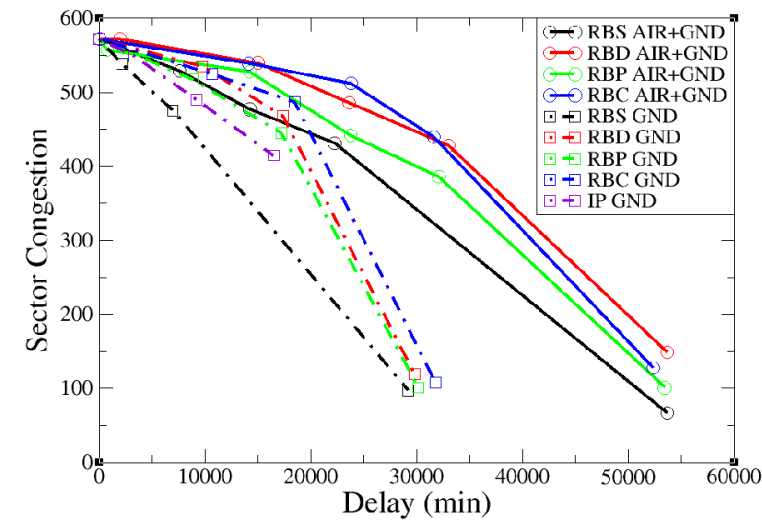

[a]

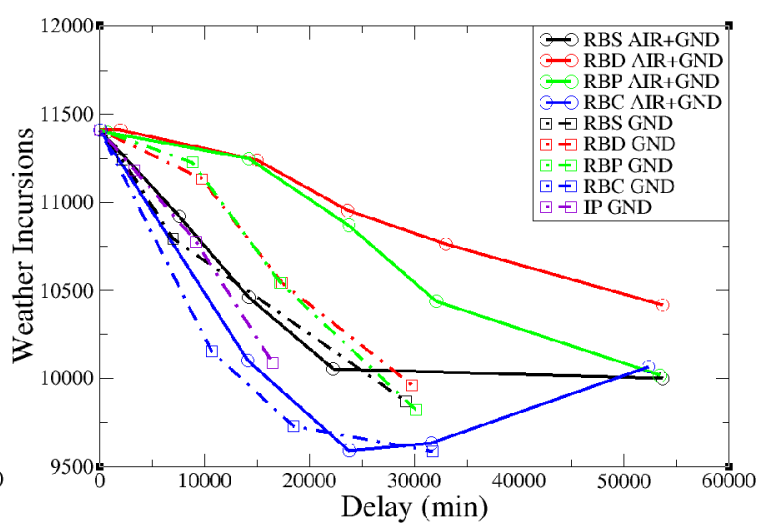

[b]

Figure 5. Impact of strategically assigning pre-departure delays only versus airborne and pre-departure delays on [a] the amount of sector congestion and [b] the number of instances that flights deviated into a region of convective weather for a bad weather day (June 19, 2007).

In general, the scheduling algorithms that assigned pre-departure delays only (black bars in Fig. 6) were found to be more equitable than the algorithms that assigned airborne and pre-departure delay (red bars in Fig. 6) when equity was measured in terms of the average airline delay using the Gini coefficient ${ }^{61}$. These results were generated from the scheduling delays that were incurred when all constraints were binding. Recall that these delays correspond to the right-most points on each of the curves in Fig. 5. As previously observed, the ration-by-schedule (RBS) algorithms tended to be the most equitable in terms of the average airline delay, and the ration-by-passenger (RBP) algorithm was the least equitable. When equity was measured in terms of the maximum airline delay, all the scheduling algorithms performed roughly the same, as illustrated by Fig. $6 \mathrm{~b}$. 

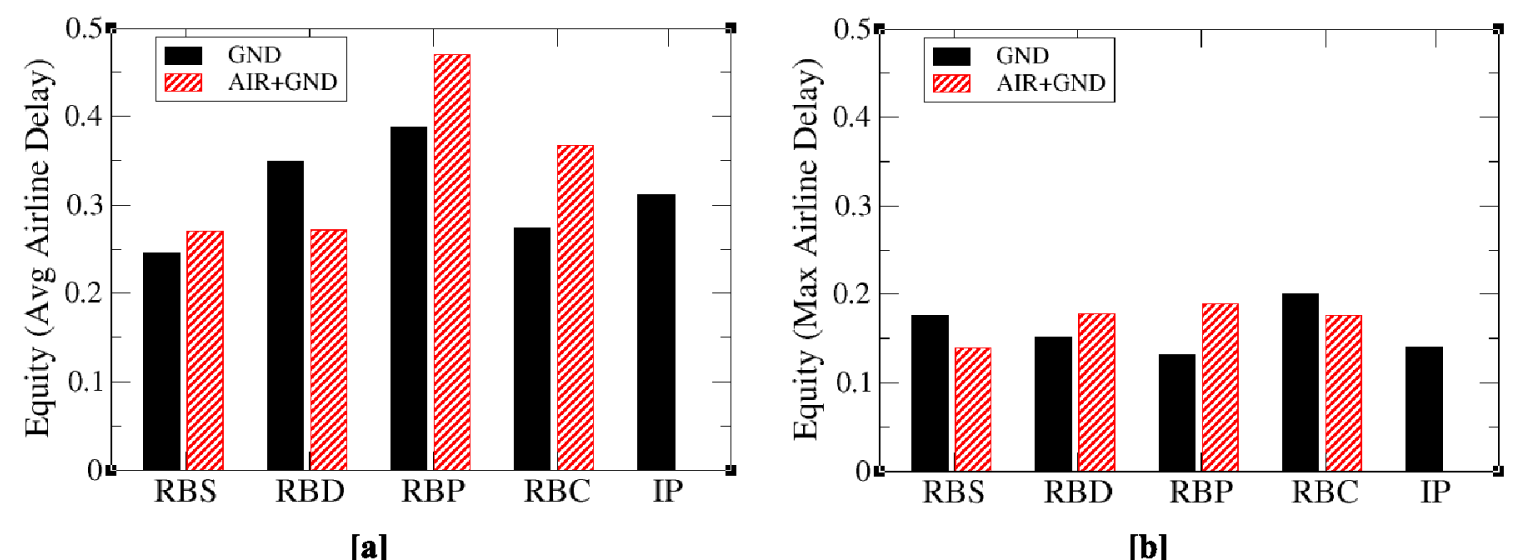

Figure 6. Impact of strategically assigning pre-departure delays only versus airborne and pre-departure delays on [a] airline equity calculated from the average airline delay and [b] airline equity calculated from the maximum airline delay for a bad weather day (June 19, 2007).

\section{Strategic versus Tactical Flight Controls}

As noted in Sub-sections IV.B and IV.C, the strategic scheduling algorithms are generally effective at limiting sector congestion when robust estimates of the sector demand and capacity are known However even after scheduling, a significant number of flights continue to intrude into regions of convective weather. To mitigate this problem, the sequential decision making approach proposed in Refs. 3 and 4 can be used to schedule flights at the strategic level while tactically rerouting flights at the local level in order to reduce the number of weather incursions. The inclusion of a tactical rerouting algorithm in the "System Planning" box in Fig. 1 was able to reduce the number of weather incursions by over a factor of four, as can be seen by comparing the solid curves in Fig. $7 \mathrm{~b}$ with the dashed curves. The non-zero weather incursion values observed in Fig. $7 \mathrm{~b}$ are the result of flights originating in a CWAM $60 \%$ probability deviation contour at the start of a re-planning interval. Results presented in this subsection assume that re-planning at the strategic-level occurred every three hours with a three-hour look-ahead interval, and tactical flight rerouting was allowed to occur every five minutes.

Although the inclusion of a tactical rerouting algorithm in the "System Planning" box in Fig. 1 can significantly reduce the number of weather incursions, the resulting reroutes lead to considerable uncertainty in the demand estimates that are used by the strategic scheduling algorithms. The affect of this uncertainty is illustrated in Fig. 7a by the dramatic increase in the observed amount of sector congestion when tactical rerouting is allowed. For example with the ration-by-congestion (RBC) algorithm, 30,000 minutes of delay corresponds to roughly 450 units of sector congestion when tactical rerouting is not allowed (see the solid blue curve in Fig. 7a). However when rerouting is allowed this same delay level results in over 600 units of sector congestion, as illustrated by the dashed blue curve.

In an effort to "sanity-check" the fast-time simulation results, the actual level of sector congestion and the number of weather incursions that were observed operationally on June 19, 2007 are indicated by the solid triangles in Fig. 7. To calculate these, the actual ETMS data from June 19, 2007 was replayed in FACET with the CWAM $60 \%$ probability deviation contours from the same date, and weather impacted sector capacities calculated from these weather contours. The delay value associated with these data points corresponds to the Aviation System Performance Metrics (ASPM) airborne delays between 6:00 am and 2:00 pm EDT for the top 75 airports in the NAS. The ASPM airborne delays were selected because it is believed that these better represent the delays that a flight would incur due to en route weather. Had the ASPM departure delays been selected, then these values would have also included the delays associated with the ten Ground Delay Programs (GDPs) that were in affect on this day. When comparing the results, it is important to keep in mind that flights in the NAS are delayed for a variety of reasons, some related to en route congestion and some not. With this in mind, the agreement between the modeled and actual results is promising. Although the results do not agree within less than $10 \%$, for example, they do indicate that the major sources of delay in the en route environment (e.g., weather) were reasonably modeled, which was the intent. 


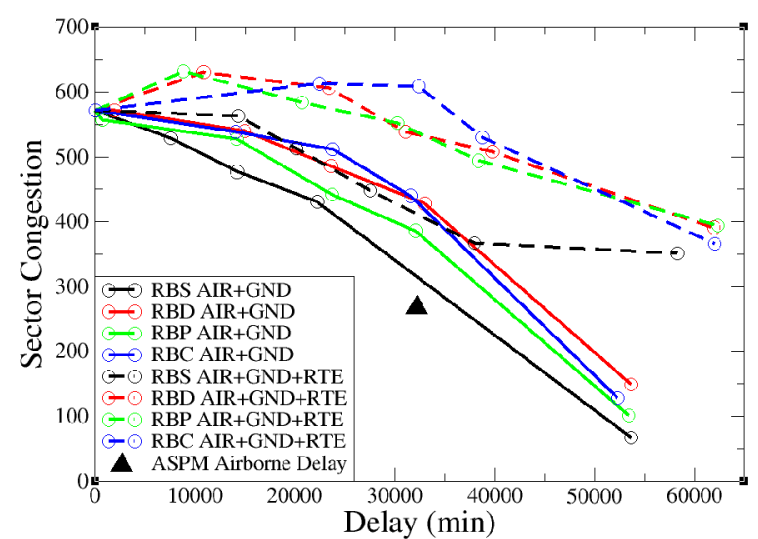

[a]

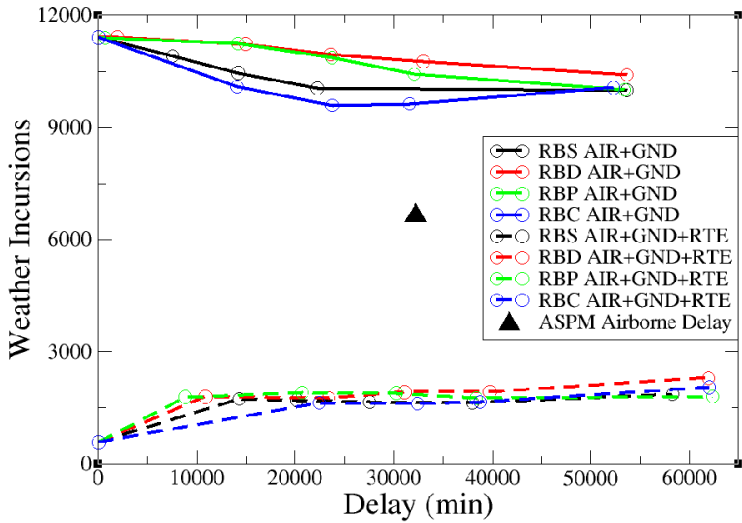

[b]

Figure 7. Effect of using tactical rerouting to dynamically adapt strategic traffic flow management controls to account for en route weather constraints on [a] the amount of sector congestion and [b] the number of instances that flights deviated into a region of convective weather for a bad weather day (June 19, 2007).

The results of the airline equity calculations with (red bars) and without (black bars) tactical weather avoidance rerouting are presented in Fig. 8. These results were generated from the scheduling delays that were incurred when all constraints were binding. When airline equity is measured in terms of the average airline delays, the introduction of tactical weather avoidance rerouting led to a general increase in equity (e.g., smaller values of the equity coefficient), as illustrated by the red bars in Fig. 8a. This is to be expected since all flights encountering regions of severe weather will be rerouted and no single airline is expected to receive preferential routing treatment given the current rerouting algorithm. When airline equity is measured in terms of the maximum airline delay, the introduction of tactical weather avoidance rerouting does not significantly change the equity results, as illustrated by the relatively small variations in the magnitudes of the bars appearing in Fig. 8b.

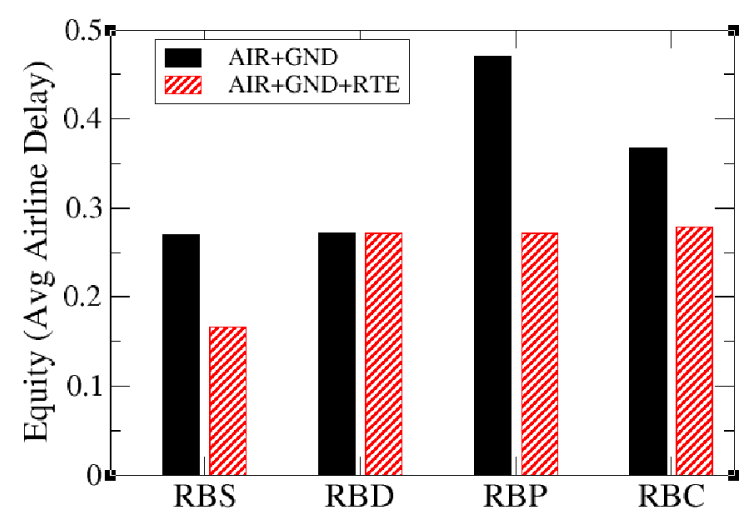

[a]

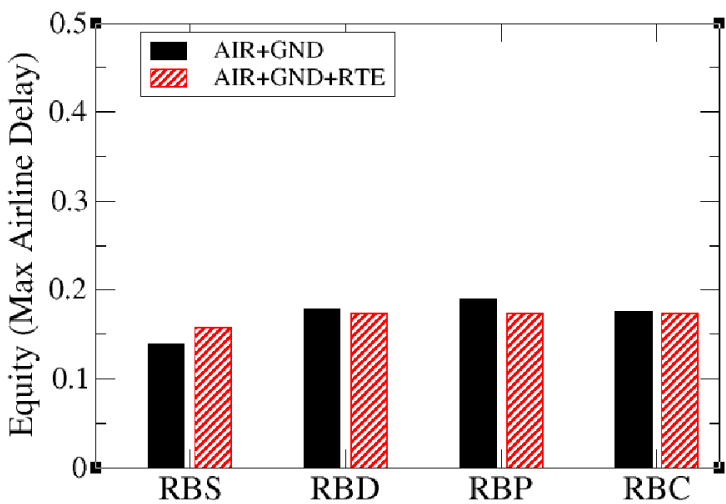

[b]

Figure 8. Effect of using tactical rerouting to dynamically adapt strategic traffic flow management controls to account for en route weather constraints on [a] airline equity calculated from the average airline delay and [b] airline equity calculated from the maximum airline delay for a bad weather day (June 19, 2007).

\section{Conclusions}

This paper presents an approach to support integrated traffic flow management decision making at both the U.S. national and regional levels that can consider trade-offs between alternative optimization and heuristic based models, strategic versus tactical flight controls, and system versus fleet preferences. At the highest-level, the key components of this approach are system inputs, demand estimation models, weather translation models, air traffic service provider planning capabilities, user planning capabilities, and metrics. Available models and data sources for each of these components are described.

Preliminary testing of this integrated approach was accomplished by implementing models for all of the key components of the approach, and conducting 85 , six-hour fast-time simulation experiments using thirteen traffic 
flow management models. The results were analyzed in terms of the total system delays, the amount of en route congestion, the number of weather incursions, and the equity of the solutions. The operational Enhanced Traffic Management System flight data from August 24, 2005 was used to develop the flight schedule, and a convective weather scenario was developed using the Convective Weather Avoidance Model data from June 19, 2007. For reference, June 19 was selected as a representative bad convective weather day.

Results indicated that longer strategic planning look-ahead times and re-planning intervals resulted in steadily decreasing levels of sector congestion for a fixed delay level. In general, the distribution of the delays amongst the users was found to be most equitable when scheduling flights using a heuristic scheduling algorithm, such as rationby-distance. Equity was the worst when using scheduling algorithms that took into account the number of passengers aboard each flight. Though the strategic scheduling models themselves were ineffective at keeping flights out of en route weather hazards, coupling the strategic model with a tactical weather rerouting model was effective at reducing en route congestion while avoiding these en route hazards. Finally, the modeled levels of en route congestion, the number of weather incursions, and the total system delays, were found to be in fair agreement with the values that were operationally observed on both the good and bad weather days.

\section{Appendix}

Using the integer programming (IP) formulation presented in Refs. 3 and 4, the airports and sectors for which a constraint exists can be expressed mathematically as follows:

Airport Departure Constraints: Number of departures from an airport, $k$, during any time period exceeds the airport departure capacity,

$$
\sum_{f: P(f, 1)=k}\left(x_{f, t}-x_{f, t-1}\right)>C_{k}(t), \forall k \in K, t \in\{1, \ldots, T\}
$$

Airport Arrival Constraints: Number of landings during any time interval exceeds the airport arrival capacity,

$$
\sum_{\mathrm{f}: \mathrm{P}\left(f, N_{\mathrm{f}}\right)=\mathrm{k}}\left(\mathrm{x}_{\mathrm{f}, \mathrm{t}}-\mathrm{x}_{\mathrm{f}, \mathrm{t}-1}\right)>\mathrm{A}_{\mathrm{k}}(\mathrm{t}), \forall k \in K, t \in\{1, \ldots, T\}
$$

Sector Capacity Constraints: Number of aircraft present in sector $j$ at time $t$ exceeds the sector capacity,

where

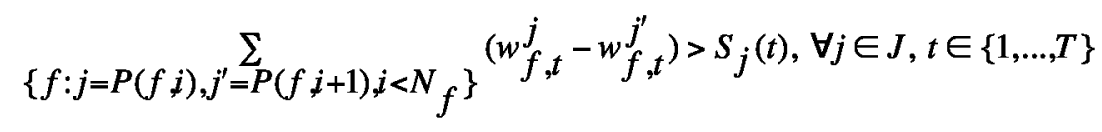

$A_{k}(t):$ time-varying arrival capacity of airport $k \in K$

$C_{k}(t)$ : time-varying departure capacity of airport $k \in K$

$F:$ set of flights

$J$ : set of sectors

$K$ : set of airports

$N_{f}$ : number of resources (i.e., sectors and airports) in the path of flight $f$

$P(f, i): i^{t h}$ sector used by flight $f, P(f, i) \in J$

$S_{j}(t)$ : time-varying sector capacity

$T:$ number of discrete time intervals that constitute the planning horizon

The binary decision variables in the model, $x_{f, t} \in\{0,1\}$, are defined as:

$$
x_{f, t}=\left\{\begin{array}{l}
1, \text { if flight f departs by time } t \\
0, \text { otherwise }
\end{array}\right.
$$


Based on the decision variables $x_{f, t}$, a set of auxiliary variables, $w_{f, t}^{j} \in\{0,1\}$, which indicate if a flight $f$ has entered sector $j$, where $j=P(f, i), 1<i<N_{f}$ by time $t$, are defined as:

$$
w_{f, t}^{j}=x \quad \sum_{m=1}^{i-1} \sum_{m, P(f, m)}
$$

\section{References}

${ }^{1}$ Sridhar, B., Chatterji, G. B., Grabbe, S., and Sheth, K., "Integration of Traffic Flow Management Decisions," $A I A A$ Guidance, Navigation, and Control Conference, Monterey, CA, Aug. 5-8, 2002.

${ }^{2}$ Wanke, C. and Greenbaum, D., "Incremental Probabilistic Decision Making for En Route Traffic Management," Air Traffic Control Quarterly, Vol. 15, pp. 299-319, 2007.

${ }^{3}$ Grabbe, S., Sridhar, B., and Mukherjee, A., "Sequential Traffic Flow Optimization with Tactical Flight Control Heuristics," AIAA Guidance, Navigation, and Control Conference, Honolulu, HI, Aug. 18-21, 2008.

${ }^{4}$ Grabbe, S., Sridhar, B., and Mukherjee, A., "Sequential Traffic Flow Optimization with Tactical Flight Control Heuristics," AIAA Journal of Guidance, Control and Dynamics, Vol. 32, No. 3, pgs. 810-820, May-June 2009.

${ }^{5}$ Song, L., Wanke, C., Greenbaum, D., Zobell, S., and Jackson, C., "Methodologies for Estimating the Impact of Severe Weather on Airspace Capacity," The $26^{\text {th }}$ Congress of International Council of the Aeronautical Sciences (ICAS), Anchorage, AK, Sept. 14-19, 2008.

${ }^{6}$ Mukherjee, A., Grabbe, S., and Sridhar, B., "Alleviating Airspace Restrictions through Strategic Control," AIAA Guidance, Navigation, and Control Conference, Honolulu, HI, Aug. 18-21, 2008.

${ }^{7}$ Grabbe, S., Sridhar, B., and Mukherjee, A., "Central East Pacific Flight Scheduling," AIAA Guidance, Navigation, and Control Conference, Hilton Head, SC, Aug. 20-23, 2007.

${ }^{8}$ DeLaura, R. and Evans, J., "An Exploratory Study of Modeling En Route Pilot Convective Storm Flight Deviation Behavior," $12^{\text {th }}$ American Meteorological Society Conf. on Aviation, Range, and Aerospace Meteorology, Atlanta, GA, Jan./Feb. 2006.

${ }^{9}$ Idris, H., Evans, A., Vivona, R., Krozel, J., and Bilimoria, K., "Field Observations of Interactions Between Traffic Flow Management and Airline Operations," AIAA $6^{\text {th }}$ Aviation, Technology, Integration, and Operations Conference, Wichita, KS, Sept. 25-27, 2006.

${ }^{10}$ Ball, M. O., Hoffman, R., Chen, C. Y., and Vossen, T., "Collaborative Decision Making in Air Traffic Management: Current and Future Research Directions," New Concepts and Methods in Air Traffic Management, edited by Bianco, L., Dell'Olmo, P., and Odoni, A. R., Springer-Verlag, New York, 2001.

${ }^{11}$ "NextGen Concept of Operations, Version 2.0," Joint Planning and Development Office, URL: http://www.jpdo.gov/library.asp [Cited July 15, 2008].

${ }^{12}$ Hekl, R. A., Lam, T. N., McMillen, E. C., Mosier, C. J., and Tarakan, R. M., "Concept of Operations for a Flight Plan Preprocessing Capability in the National Airspace System," AIAA Aviation, Technology, Integration, and Operations Conference, Los Angeles, CA, Oct. 1-3, 2002.

13،"Enhanced Traffic Management System (ETMS)," Report No. VNTSC-DTS56-TMS-002, Volpe National Transportation Center, U.S. Department of Transportation, Cambridge, MA, Oct. 2005.

${ }^{14}$ Chan, W. N. and Green, S. M., "Considerations for Using Low Temporal Resolution Weather Information in Air Traffic Decision Making," $6^{\text {th }}$ AIAA Aviation, Technology, Integration, and Operations Conference, Wichita, KS, Sept. 25-27, 2006.

${ }^{15}$ Fahey, T., et al., "Forecasts of Convection for Air Traffic Management Strategic Decision Making: Comparison of User Needs and Available Products," Proceedings of the $12^{\text {th }}$ Conference on Aviation, Range, and Aerospace Meteorology, Atlanta, GA, 2006.

${ }^{16}$ Krozel, J., McNichols, W. M., Prete, J., Lindholm, T., "Causality Analysis for Aviation Weather Hazards," The 26 Congress of International Council of the Aeronautical Sciences (ICAS), Anchorage, AK, Sept. 14-19, 2008.

${ }^{17}$ The Rapid Update Cycle (RUC), National Oceanic \& Atmospheric Administration, URL: http://ruc.noaa.gov, [cited Dec. $23,2008]$.

${ }^{18}$ Ivaldi, C. and Reynolds, D., "Upgrade and Technology Transfer of the San Francisco Marine Stratus Forecast System to the National Weather Service," $12^{\text {th }}$ Conference on Aviation, Range, and Aerospace Meteorology, Atlanta, GA, January, 2006.

${ }^{19}$ Kopardekar, P., Bilimoria, K., and Sridhar, B., "Initial Concepts for Dynamic Airspace Configuration," $7^{\text {th }}$ AIAA Aviation Technology, Integration and Operations Conference (ATIO), Belfast, Northern Ireland, Sept. 18-20, 2007.

${ }^{20}$ Xue, M. and Kopardekar, P., "Airspace Sector Redesign Based on Voronoi Diagrams," AIAA Guidance, Navigation, and Control Conference, Honolulu, HI, Aug. 18-21, 2008.

${ }^{21}$ Erzberger, H., "CTAS: Computer Intelligence for Air Traffic Control in the Terminal Area," NASA TM 103959, July, 1992.

${ }^{22}$ Bilimoria, K. D., Sridhar, B., Chatterji, G., Sheth, K. S., and Grabbe, S. R., "Future ATM Concepts Evaluation Tool," Air Traffic Control Quarterly, Vol. 9, No. 1, March 2001.

${ }^{23}$ Rhodes, L. S., Rhodes, L. R., Beaton, E. K., "CRCT capabilities detailed functional description," MITRE Tech. Rep. 00W0000302, Mar., 2001. 
${ }^{24}$ Krozel, J., Rosman, D., and Grabbe, S., "Analysis of En route Sector Demand Error Sources," AIAA Guidance, Navigation, and Control Conference, Austin, TX, Aug. 11-14, 2003.

${ }^{25}$ Wanke, C., Mulgund, S., Greenbaum, D., and Song, L., "Modeling Traffic Prediction Uncertainty for Traffic Management Decision Support," AIAA Guidance, Navigation, and Control Conference, Providence, RI, Aug. 16-19, 2004.

${ }^{26}$ Sridhar, B., Grabbe, S. R., and Mukherjee, A., "Modeling and Optimization in Traffic Flow Management," Proceedings of the IEEE, Vol. 96, No. 12, Dec. 2008.

${ }^{27}$ Menon, P. K., Sweriduk, G. D., and Bilimoria, K. D., "A New Approach to Modeling, Analysis and Control of Air Traffic Flow," AIAA Guidance, Navigation, and Control Conference, Monterey, CA, 2002.

${ }^{28}$ Roy, S., Sridhar, B., and Verghese, G. C., "An Aggregate Dynamic Stochastic Model for Air Traffic Control," Proc. of the $5^{\text {th }}$ USA/Europe ATM R\&D Seminar, Budapest, Hungary, June 23-27, 2003.

${ }^{29}$ Sun, D. and Bayen, A. M., "Multicommodity Eulerian-Lagrangian Large-Capacity Cell Transmission Model for En Route Traffic," AIAA Journal of Guidance, Control, and Dynamics, Vol. 31, No. 3, 2008.

${ }^{30}$ Sheth, K. S., Amis, T. A., and Gutierrez-Nolasco, S., "Analysis of Probabilistic Weather Forecasts for Use in Air Traffic management," Aviation, Range and Meteorology, Special Symposium on Weather-Air Traffic Management Integration, 89 Annual American Meteorological Society, Phoenix, AZ, Jan. 12-15, 2008.

${ }^{31}$ Song, L., Wanke, C., Greenbaum, D., Zobell, S., and Jackson, C., "Methodologies for Estimating the Impact of Severe Weather on Airspace Capacity," The $26^{\text {th }}$ Congress of International Council of the Aeronautical Sciences (ICAS), Anchorage, AK, Sept. 14-19, 2008.

${ }^{32}$ Klein, A., Cook, L., Wood, B., and Simenauer, D., "Airspace Capacity Estimation Using Flows and Weather-Impacted Traffic Index," IEEE Integrated Communications Navigation and Surveillance (ICNS) Conference, Bethesda, MD, May 5-7, 2008.

${ }^{33}$ Klein, A., Cook, L., and Wood, B., "Airspace Availability Estimation for Traffic Flow Management Using the Scanning Method," IEEE/AIAA 27 $7^{\text {th }}$ Digital Avionics Systems Conference, St. Paul, MN, Oct. 26-30, 2008.

${ }^{34}$ Krozel, J., Mitchell, J., Polishchuk, V., and Prete, J., "Capacity Estimation for Airspace with Convective Weather Constraints," AIAA Guidance, Navigation and Control Conference, Hilton Head, SC, Aug. 20-23, 2007.

${ }^{35}$ Martin, B. D., "Model Estimates of Traffic Reduction in Storm Impacted En Route Airspace," AlAA Aviation, Technology, Integration, and Operations Conference, Arlington, VA, Sept. 18-20, 2007.

${ }^{36}$ Callaham, M., DeArmon, Cooper, A., Goodfriend, J., Moch-Mooney, D., and Solomos, G., "Assessing NAS Performance: Normalizing for the Effects of Weather," Proc. of the $4^{\text {th }}$ USA/Europe ATM R\&D Seminar, Santa Fe, NM, 2001.

${ }^{37}$ Idris, H., Vivona, R., Penny, S., Krozel, J., and Bilimoria, K., "Operational Concept for Collaborative Traffic Flow Management based on Field Observations," $5^{\text {th }}$ AIAA Aviation Technology, Integration and Operations Conference (ATIO), Arlington, VA, Sept. 26-28, 2005.

${ }^{38}$ Bertsimas, D. and Patterson, S. S., "The Air Traffic Flow Management with En route Capacities," Operations Research, Vol. 42, pp. 249-261, 1994.

${ }^{39}$ Lindsay, K., Boyd, E., and Burlingame, R., "Traffic Flow Modeling with Time Assignment Model," Air Traffic Control Quarterly, Vol. 1, pp. 255-276, 1994.

${ }^{40}$ Hunter, G., "Toward an Economic Model to Incentivize Efficient and Cooperative Traffic Flow," The 26 ${ }^{\text {th }}$ Congress of International Council of the Aeronautical Sciences (ICAS), Anchorage, AK, Sept. 14-19, 2008.

${ }^{41}$ Jakobovits, R., Kopardekar, P., Burke, J., and Hoffman, R., "Algorithms for Managing Sector Congestion Using the Airspace Restriction Planner," Proc. of the $7^{\text {th }}$ USA/Europe ATM R\&D Seminar, Barcelona, Spain, 2007.

${ }^{42}$ Wells, A. T. and Wensveen, J. G., Air Transportation: A Management Perspective, Fifth Edition, Brooks/Cole - Thomson Learning, Belmont, CA, 2004.

${ }^{43}$ Berge, M. E., Hopperstad, C. A., and Haraldsdottir, A., "Airline Schedule Recovery in Collaborative Flow Management with Airport and Airspace Capacity Constraints," Proc. of the $5^{\text {th }}$ USA/Europe ATM R\&D Seminar, Budapest, Hungary, June 2327, 2003.

${ }^{44}$ Hane, C. A., Barnhart, C., Johnson, E. L., Marsten, R. E., Nemhauser, G. L., and Sigismondi, G., "The Fleet Assignment Problem: Solving a Large-Scale Integer Program," Mathematical Programming, Vol. 70, No. 1-3, pgs. 211-232, October, 1995.

${ }^{45}$ Sheth, K. and Gutierrez-Nolasco, S., "Incorporating User Preferences in Collaborative Traffic Flow Management," AIAA Guidance, Navigation, and Control Conference, Honolulu, HI, Aug. 18-21, 2008.

${ }^{46}$ Henderson, J., Idris, Kicinger, R., Krozel, J., Wang, D., Sheth, K. S., "Airline and Service Provider Collaborative Algorithms for Flight to Resource Allocation," $g^{\text {ih }}$ AIAA Aviation Technology, Integration and Operations Conference (ATIO), Hilton Head, SC, Sept. 21-23, 2009.

${ }^{47}$ Bradford, S., Knorr, D., and Liang, D., "Performance Measures for Future Architecture," Proc. of the $3^{\text {rd }}$ USA/Europe ATM $R \& D$ Seminar, Napoli, Italy, June 13-16, 2000.

${ }^{48}$ Bolczak, C. N., Hoffman, J. H., Jensen, A. J., and Trigeiro, W. W., "National Airspace System Performance Measurement: Overview," MTRE Tech. Rep. MTR97W0000035, Aug. 1997.

${ }^{49}$ Chatterji, G.B. and Sridhar, B., "National Airspace System Delay Estimation Using Weather Weighted Traffic Counts," AIAA Guidance, Navigation, and Control Conference, San Francisco, CA, Aug., 2004.

${ }^{50}$ Sridhar, B. and Swei, S., "Relationship Between Weather, Traffic and Delay Based on Empirical Methods," $6{ }^{\text {th }} A I A A$ Aviation Technology, Integration and Operations Conference (ATIO), Wichita, KS, Sept., 2006. 
${ }^{51}$ Sridhar, B. and Swei, S. S. M., "Classification and Computation of Aggregate Delay Using Center-based Weather Impacted Traffic Index," $7^{\text {th }}$ AIAA Aviation Technology, Integration and Operations Conference (ATIO), Belfast, Northern Ireland, Sept. 18-20, 2007.

${ }^{52}$ Klein, A., "NAS/ATM Performance Indexes," Proc. of the $7^{\text {th }}$ USA/Europe ATM R\&D Seminar, Barcelona, Spain, 2007.

${ }^{53} \mathrm{Xu}$, N., Donohue, G., Laskey, K. B., and Chen, C. H., "Estimation of Delay Propagation in the National Aviation System Using Bayesian Networks," Proc. of the $7^{\text {th }}$ USA/Europe ATM R\&D Seminar, Barcelona, Spain, 2007.

${ }^{54}$ Laskey, K. B., Xu, N., and Chen, C. H., "Propagation of Delays in the National Airspace System," Proc. of the $22^{\text {th }}$ Conf. on Uncertainty and Artificial Intelligence, Cambridge, MA, 2006.

${ }^{55}$ Churchill, A. M., Lovell, D. J. and Ball, M. O., "Examining the Temporal Evolution of Propagated Delays at Individual Airports: Case Studies," Proc. of the $7^{\text {th }}$ USA/Europe ATM R\&D Seminar, Barcelona, Spain, 2007.

${ }^{56}$ Bratu, S. and Barnhart, C., "An Analysis of Passenger Delays Using Flight Operations and Passenger Booking Data," Air Traffic Control Quarterly, Vol. 13, No. 1, pp. -129, 2005.

${ }^{57}$ Air Traffic Operations Network (OPSNET), U.S. Federal Aviation Administration, url: http://www.apo.data.faa.gov [cited July 15, 2008].

${ }^{58}$ Rios, J. and Ross, K., "Solving High-Fidelity, Large-Scale Traffic Flow Management Problems in Reduced Time," $8^{\text {th }}$ AIAA Aviation Technology, Integration and Operations Conference (ATIO), Anchorage, AK, Sept. 14-19, 2008.

59''Schedule B-43 Aircraft Inventory 2007", Bureau of Transportation Statistics, url:

http://www.bts.gov/programs/airline_information/schedule_b43/2007/ [cited June 23, 2009].

${ }^{60}$ Cormen, T. H., Leiserson, C. E., Rivest, R. L., and Stein, C., Introduction to Algorithms, 2nd ed., MIT Press, Cambridge, MA, 2001.

${ }^{61}$ Sen, A., On Economic Inequality, Oxford, England, Clarendon Press, 1973. 